\title{
LA CERTIFICACIÓN NOTARIAL UN COMPROMISO SOCIAL DEL NOTARIO
}

Abel Hernández Zúñiga*

Resumen: A partir de la vigencia de la actual Ley del Notariado para el Estado de Guanajuato (1 de enero de 2007), al notario público le fue confirmado su compromiso legal, moral y social con su actividad autenticadora. Por ello la actualización en sus conocimientos resulta eficaz para mantener el equilibrio social; ya que al aplicar conceptos vigentes el fedatario público en la especie el notario, contribuye a la legalidad y a la paz social. Por ello la importancia de la actualización constante del profesional del derecho investido de fe pública (notario).

Palabras clave: Notario Público, Certificación Notarial, Actualización, Legalidad, Conocimientos, Compromiso, Obligación, Ley.

Abstract: The actual Notary Public Statute of the State of Guanajuato (January 1, 2007) has confirmed the legal, moral and social obligation of the notary public in authenticating documents. As a result, updating their knowledge would be a measure of an effective social stability, because when they apply their concepts as public officers contribute to maintain legality and social peace. That is the reason why the notary public has to update their knowledge in the best of the people that they serve.

Keywords. Notary Public, Notary Authentication, update, legality, Comitment, obligation,

El objetivo primordial del presente trabajo es ubicar de forma justa la importancia de la certificación notarial en el Estado de Guanajuato, como responsabilidad social del notario, para lo que se desarrolla un bosquejo de la situación actual en el ámbito legal y social del notariado guanajuatense.

En el Periódico Oficial número 134 del Gobierno del Estado de Guanajuato, tercera parte de fecha 22 de agosto de 2006, bajo Decreto número 294, fue publicada la actual Ley del Notariado para el Estado de Guanajuato, misma que entró en vigor el día $1^{\circ}$ de enero de 2007. Dicha Ley prevé el sistema obligatorio de actualización que tiene por objeto la actualización permanente de los notarios, además de señalar la forma en que la certificación debe ser regulada.

\footnotetext{
* Maestro en Amparo. Actualmente cursa la Maestría en Política y Gestión Pública.
} 
Pero aún y cuando esta figura es una disposición de carácter legal, la realidad es que por muchos no se ha alcanzado a ver a la certificación notarial como un compromiso para con la profesión y con el servicio que se presta, ya que se ha desvirtuado su objetivo y razón de ser.

Sumado a lo anterior también es cierto que la figura legal de la certificación notarial ha encontrado un vacio, ya que a pesar de ser de carácter obligatorio no cuenta con una sanción especifica en el cuerpo de la Ley, o lo que es lo mismo no hay una forma de coacción a su incumplimiento, cosa que de ello da cuenta La Ley del Notariado para el Estado de Guanajuato en el Capítulo Duodécimo denominado "De la Responsabilidad Notarial y sus Sanciones", de donde se desprende que no existe expresamente una sanción.

Teniendo como base el artículo 3 de la Ley del Notariado para el Estado de Guanajuato que dice que el notario es un profesional del derecho investido de fe pública para ejercer la función notarial, y tomando en consideración que la propia Ley que regula la función es de interés social y de orden público, está más que justificada la obligatoriedad que tiene el notario para mantenerse actualizado, ahora bien, y si a esto le añadimos que el derecho como ciencia jurídica se transforma constantemente, se eleva la imperiosa necesidad de que el profesional del derecho, en la especie el notario, deba estar al día en sus conocimientos.

Si el notario tiene la obligación desde el punto de vista legal de cumplir con las disposiciones notariales, por qué no tener el compromiso social y profesional de hacerlo. Éticamente el notario tiene un compromiso social con los rogantes de sus servicios, ya que las transacciones jurídicas que estos realicen y que deban autenticar son la razón de ser y de existir del fedante notarial.

La afectación e influencia de la actualización (de conocimientos) de un notario en la vida pública y privada de las personas es más que relevante, ya que es algo cotidiano que las personas adquieran o transfieran inmuebles, otorguen un poder, un testamento, certifiquen documentos, ratifiquen sus operaciones legales o soliciten se de fe de hechos que les constituyen un interés, por citar un mínimo de servicios frecuentemente solicitado por los rogantes del servicio fedante y que necesariamente tienen que ser ante la fe de un notario público, es así como el notario juega un rol más que significativo en los actos jurídicos celebrados por los individuos que conforman la sociedad. 
Si bien es cierto que el notario a la obtención del fíat debió cumplir una serie de requisitos entre ellos ser licenciado en derecho titulado o su equivalente y ser notario público titulado o su equivalente, claramente implica que el pretensor del fíat es una persona capacitada académicamente para desempeñar dicha función; luego entonces y en apego a la realidad hay que decir que entre el momento de la investidura de fe pública (otorgamiento del fíat) para ejercer la función notarial y el "hoy" dicho en cualquier momento del tiempo, se han transformado diversas normas de observancia notarial que deben ser atendidas.

Es así que el notario público con esa responsabilidad acuestas se ha convertido en un agente garante de legalidad, ya que su relevante función en los actos jurídicos requieren de su más profunda honradez y dedicación profesional, toda vez que el notario de acuerdo con la legislación local de la materia es el que asesora y recibe la voluntad de las partes, la interpreta y le da forma legal; el hecho de que el notario luego de recibir imparcialmente la voluntad de las partes, interpretarla y darle forma legal a la misma, llevándola materialmente al instrumento público, implica que el profesional del servicio notarial tiene amplio conocimiento sobre el acto que desarrolla y la implicación en la vida jurídica de las personas.

En el proceso del conocimiento profesional se han distinguido dos momento a decir: el primero la adquisición de conocimientos académicos que permitan desempeñar una profesión y el segundo como aquel que permita actualizar los conocimientos ya adquiridos, por ello me atrevo a distinguir entre la adquisición de conocimiento nuevo, la confirmación, reafirmación y actualización; en el campo del derecho notarial existen temas de constante evolución y que requieren de una actualización tales como: la materia fiscal. Así pues, atrevámonos a llevar a la imaginación la falta de actualización en materia de impuestos, tema en donde la responsabilidad es altamente grave.

Por su parte la Ley del Notariado para el Estado de Guanajuato como ordenamiento local establece en materia de actualización que:

Artículo 153.- "La certificación notarial es el sistema de carácter obligatorio que tiene por objeto la actualización permanente de los notarios con relación a los conocimientos propios de la función notarial.

La certificación notarial será obligatoria y tendrá una vigencia de dos años al cabo de los cuales deberá refrendarse." $y$, "Artículo 154.- La certificación notarial tendrá por objeto:

I. Mantener un nivel de conocimiento actualizado, que permita ofrecer a la socie- 
dad, servicios notariales profesionales, éticos y de calidad;

II. Incrementar el nivel de conocimientos de quienes ejercen la función notarial;

y

III. Estimular la vida académica y profesional de los Notarios."

Como puede observarse los poderes Ejecutivo y Legislativo han cumplido con el compromiso social y legal en la materia; el primero en haber participado en una iniciativa que regulara la prestación del servicio notarial a la sociedad de forma profesional, ética y de calidad, y el segundo por la apertura en el debate y refrendo de su compromiso con la sociedad en dotarla de leyes que le permitan el desarrollo seguro de su vida jurídica y la de su patrimonio, y evidencia de esto último es el debate sostenido en la Cámara sobre el tema de la Certificación ya que de forma breve pero de manera muy clara justifica la necesidad de la actualización notarial:

“Diario de los Debates de la Cámara de Diputados del Estado de Guanajuato de fecha 15 de agosto de 2006, página 5 del Dictamen:

certificación notarial.

Se propone un sistema obligatorio de certificación notarial, cuyo objeto es la actualización permanente de los notarios con relación a los conocimientos propios de la función notarial, lo que representa un avance y modernización de dicha actividad; y que siendo ello en beneficio tanto del servicio público notarial como de los propios notarios, la Comisión de Justicia la abrazó con beneplácito y con gran interés, pues ello le viene a dar también modernidad y eficiencia a la función."

Evocando brevemente a la Unión Internacional del Notariado Latino que en uno de sus actos gremiales declaró que el notario debe ejercer su función autenticadora: interpretando y aplicando la ley bajo una estricta adquisición de conocimientos específicos en los temas que involucran al notariado y tomando en forma diligente las consideraciones e indicaciones de sus órganos gremiales en los temas de formación profesional.

Consiguientemente el sistema legal obligatorio y profesionalmente correcto, debe contemplar una forma eficaz y práctica de evaluar la calidad del conocimiento adquirido que vaya más allá de la simple sumatoria de puntos como hasta ahora se ha realizado y que refleje el beneficio para la sociedad.

En concreto, el notario como profesional del derecho investido de fe pública y contribuyente activo al tema de la legalidad, debe refrendar su 
compromiso con la esfera social a la que sirve continuando con el ejercicio de su función de manera ética y profesional, conceptos estos últimos que son alimentados con la promoción de valores morales y jurídicos, que a su vez hacen la base para un servicio de calidad en una expresión amplia.

Luego entonces, el notario debe formar y formarse como un virtuoso del derecho y ello solo puede alcanzarse mediante la capacitación y actualización constante.

\section{BIBLIOGRAFÍA}

Giménez Arnau, Enrique, Derecho Notarial, ed. EUNSA, Pamplona, España, 1976, 2a edición, p. 881.

Periódico oficial del gobierno del Estado de Guanajuato, Número 134, 22 de agosto de 2006, Decreto 294, Quincuagésima Novena Legislatura Constitucional del Estado Libre y Soberano de Guanajuato, p. 44.

Asociación Nacional del Notariado Mexicano, A. C., XII Jornada Notarial Iberoamericana, ed. Casa Aldo Manuzio, D.F., México, 1a edición, 1984, p. 169.

Guiza Alday, Francisco, Ley del Notariado para el Estado de Guanajuato, ed. Yussim, León, Gto., 2a edición, 2007, p. 200.

Aguilar Villanueva, Luis F, Gobernanza y gestión pública, ed. Fondo de Cultura Económica, D.F., México, 2a edición, 2006, p. 450.

Fleitman, Jack, Evaluación integral para implantar modelos de calidad, ed. Pax, D.F., México, 2007, 1a edición, p. 409. 
